\title{
A REVIEW ON DIVERSE ASPECTS OF SCHEDULE CASTES OF INDIA
}

\author{
Medhe R. $S^{a}$, Archana Kujur ${ }^{b}$ \\ Research Scholar ${ }^{\mathrm{a}}$, Assistant Professor ${ }^{\mathrm{b}}$ \\ Department of Geography, School of Earth Sciences, \\ Central University of Karnataka-585367, Kalaburgi, Karnataka, India. \\ ravindramedhe1@gmail.com ${ }^{\mathrm{a}}$, archana.fe.k@gmail.com ${ }^{\mathrm{b}}$
}

\begin{abstract}
This paper giving review of diverse aspects of scheduled castes in India. A brief overview of the caste system and discusses the types of groups and their social, economic, political, educational and cultural aspects too. This paper try to show the variation between developments of various group of scheduled castes. Through this paper we can say that there is region wise and caste wise variation in the process of development. Religion conversion from Hindu to other is also important factor in the process of development of scheduled castes.
\end{abstract}

Keywords:Scheduled Castes, Aspects, Social, Economic, Political

Academic Discipline and Sub-Disciplines: Geography,Social Geography

\section{Type: Review paper \\ INTRODUCTION}

Discrimination, violence are worldwide social problem, but nature of these problems are varies region to region. In outside India concern it is racial violence but in India it is caste based violence. Scheduled castes are more vulnerable section of the Indian society by non-scheduled castes part of the Indian society.

The social development of the world has been geared up in the last century. A large section of Indian population called as 'untouchables' was deprived of their basic, legitimate, human rights to live in dignity. They suffered from many inhuman atrocities and disabilities. However, the factor that was most striking was the institution of 'untouchability'. The so-called untouchables (now designated as Scheduled Castes) occupied the lowest rank in the social hierarchy of Hindu caste system. They were the most oppressed and downtrodden of the Indian society. They were always exploited socially, economically, educationally and culturally too by the upper castes (Jagan Karade, 2014, Dr. Rukhsana, et. al. 2014). Professor M. N. Srinivas has describe a dominant caste in these words. They (Low caste people) were without exception subjugated and engaged in low ranking occupations. They were generally engaged in casual agricultural labor in the field of dominant castes. The history of categorizing some caste as scheduled castes commenced with the government of India Act, 1935. This step, on the part of the then British Government, was meant to treat the most oppressed and exploited castes with a degree of special political dispersion. Most of these castes were known as 'untouchable' in the context of the Hindu social structure. Thus the 'scheduled caste' category initially comprised castes that were isolated and disadvantaged by their untouchability; i.e. there low status in the traditional Hindu hierarchy, which exposed them to an oppressive life, characterized by a blatant deprivation of opportunities.

In India most of atrocities against SCs originate from upper Hindu castes. Each region in India has dominant castes such as Patidars in Gujrat, Marathas in Maharashtra, Okkaligas and Lingayats in Karnataka, Reddis and Kammas in Andhra Pradesh, Jats in Haryana, Yadavas and Kurmis in Bihar and so on. They (low caste people) were without exception subjugated and engaged in low ranking occupations. They were generally engaged in casual agricultural labor in the field of the dominant caste. (Lancy Lobo, 1994). According to 1950 presidential order only Dalit who professed Hindu religion could be treated as Scheduled Caste (SC). After this presidential order there were two amendments to it - in 1956 and 1990 - to grant Scheduled Caste status to Sikhs and Buddhists also. (Hindu, 16/11/2012, 06/03/2013,) Accordingly, this review will begin with a brief general discussion of scheduled castes.

According to various studies a specific caste(s) in each state dominating educational opportunities. Likewise Mahars of Maharashtra, Jatavas of Uttar Pradesh, Addharmins of Punjab, Malas and Madigas of Andhra Pradesh, Pulayas of Kerala etc. Studies have also shown that the representation of SCs in education is lower than there proportionate representation in the population which is attributed to their poor socio - economic background. Further as a whole, the growth of education has not been uniform among them and their capacity to utilize the privileges has tended to vary from one subgroup to another. According to G. G. Wankhede (2001) in his paper, all the three decades (1961 to 1981) show that there is very poor representation at higher level of education at the SC level between the castes as compared to other levels of education. When compered within the SCs and between the castes mahar, chambhar, dhor, khatik and lingader have a better performance than castes like mang, bhangi and holar. On the contrary, the mang caste shows continued poor literacy rates and educational levels all through the three decades. The mahar have a special history of social, political and cultural movements and therefore show better response in education including higher / technical education.

In an embarrassment of sorts for the state government, the Punjab and Haryana high court has observed that reservation in plots meant for scheduled caste was possibly being misused by the powerful and affluent SC families or the general 
category persons. (Saurabh Mauk, 2014).The leading caste as an occupational mobility is concerned. After the religious conversion, the Buddhists people threw their traditional attitudes, beliefs and customs. Therefore, their life style has undergone changed. Buddhists community is more aware about the educational and occupational development and their rights than other communities in the schedule. Hence, the development of the Buddhists could be treated as an ideal model for other Backward Classes.

Discrimination against Dalit's covered the entire spectrum of social, economic, and political activities, from withholding of rights to killings and was not solely practiced by high-caste Hindus against the lower castes and Dalit's. The stratification within the Dalit community also resulted in discrimination by higher-level Dalit's against lower-level Dalit's. There was also discrimination within the Christian community by older, established ancestral Christians against more recent Dalit Christian converts (US Department of State, 2006).G.G. Wankhede (2001) writing in his paper after analyzing their social and cultural background, the scheduled castes in general in the country and in the state in particular do not form a monolithic group and have a social hierarchy and practice of untouchability among themselves. Culture is affecting factor on our daily life. It is related to development of our social, economic, political and educational life. It is a base of all other things. In scheduled castes each caste having its own separate social and cultural identity with a social hierarchy and practice of untouchability among themselves.

In the last two elections of 2004 and 2009 the countries two biggest political parties, the Congress and the Bharatiya Janata Party gave tickets to only three scheduled caste (SC) candidates between them to contest from general seats. This means that the two parties gave less than $1 \%$ of their tickets in general seats to SC candidates.While only SC's can contest the 84 seats reserved for them as of 2009. Across the country the Bahujan Samaj Party that gave substantial numbers of tickets to SC candidates in general seats 83 of its 333 candidates in open seats in 2004 were SCs. Among the states Tamil Nadu led the pack in 2004 with $22 \%$ of all candidates to general seats. In 2009, Maharashtra was slightly ahead of Tamil Nadu at 20\%. (Rukmini S. Hindu, 2014).

The Pratidhi nongovernment organization has been carried on study on the cases of sexual abuse of minors based on secondary data source 60 cases reported between November 2012 and October 2013. After monitoring the profile of the 60 victims, the Scheduled Caste were found to be the most vulnerable (Hindu, 1/5/2014). Neeru Sharma saying in her article Punjab is the fifth number of state for Dalit atrocities among all the states of the country. In Punjab scheduled castes people condition is better than the other states because of cultural impact of Sikhism and Islam and relatively less presence and influences of Brahmans. On $7^{\text {th }}$ November 2012 mob of over 1800 person attacked on three Dalit colonies looted and torched the dwellings of Naikkankottai village in the district of Dharampuri. The rough estimate of the loss was Rs. 6.95 Crore (Hindu, 11/13/2012). In 2010 - 11, the Delhi government allocated Rs 1901.56 crore under the Scheduled Caste Sub-Plan (SCSP), but it spend only Rs 197.63crore. The rest of the money was diverted for projects that don't directly benefited Scheduled Caste in the Capital(Deccan Herald, 7/9/2012).

In the month of September 2011 the Delhi Government had been decided to distribute 15000 flats free of cost to Scheduled Caste (SC) families residing in slums across the capital. The total amount budget of SC/ST welfare department was unable to spend the funds; that's why the Delhi Government had planned to distribute flats free of cost to scheduled caste families residing in slums, the sources said. (Pioneer, 9/17/2011). In union budget of 2015- 16 Scheduled Caste have been allocated only Rs 30,850 crore (Rs 43,208 crore in 2014 - 15). As per Scheduled Caste Sub Plan the SCs should be allocated 16.6 percent of the plan outlay, which amount to Rs. 77,236 crore towards SCSP; National Campaign on Dalit Human Rights (NCDHR) General Secretary Paul Divakar said in a statement.(The Hindu, 02/03/2015).

The reservation policy has ensured that many scheduled castes people entered government service and reached the higher echelons of the power structure, but they comprise only a fraction of population in the state. The majority languishes low-end jobs, on the fringes of the poverty line. In most part of India, there is a correlation between economic status and the structural position of castes. The reason is that, historically higher castes had better access to occupation, income and assets than lower castes. In Hindu society, occupation was one of the defining features of the caste hierarchy, with socially valued occupation bestowing high socio-economic status on caste members. In the modern context, there has been a losing of the caste - occupation linkage.

A dynamic occupational shift has not occurred however and high end jobs continue to be the preserve of the upper castes and, now increasingly high income classes. Government policies have ensure that there has been a significant degree of occupational diversity among the scheduled castes, still constitutes a sizable chunk of the low income population with poor human development indicators. Scheduled castes ownership of land is minimal and the majority of landholders have small and unviable holdings. Director of Horticulture, Haryana, Panchkula, says in his report of 2401-Crop Husbandary-789Special Component Crops Plan Scheme for Schedule Caste (SB No. 98): Integrated Horticulture Development Plan Scheme for Scheduled Caste Families for the year 2014-15. To the additional chief secretary of Govt. Haryana, agriculture department. The scheduled castes families which have less land holdings in the State can be benefited by horticultural crops which are more employment generating and remunerative. Land is not only economical source but also social status and many times it used as a weapon to dominant low caste people by high caste people. According to 2011 census total scheduled caste population of Maharashtra is 13275898 . Out of this 6767759 are male population and 6508139 are female population. Pune is the highest scheduled castes population district in Maharashtra, Nagpur is second Thane, Solapur, and Nanded following that. Highest rural scheduled caste population located in Nanded district that is 473434 after that Ahmednagar, Solapur, Buldhana and Latur. Likewise urban population is located in Pune, Thane, Nagpur, Mumbai suburban and other district. 


\section{ISSN $2321-1091$ \\ Volume $10 \mathrm{Number} 1$ \\ Journal of Social Sciences Research}

The Scheduled Castes of Maharashtra are not different from their community brethren in the rest of the states of the country. They have also suffered a lot and were deprived of opportunities in various walks of life in different regions of the state. In protest of this, two large and effective social protest movements (Mahar, and Non-Brahmin Movements) ensued in Maharashtra in twentieth century. The Mahar movement brought those much smaller untouchable castes in degree of awareness and unity. That enabled them to create a political party, a system of hostels, schools and colleges and an effective Buddhist conversion movement before the death of national leader Dr. B.R. Ambedkar in 1956 (Ramotra, 2000). Examined in Maharashtra the impact of embracing Buddhism on 14th October in 1956 brought social, cultural and occupational change among Mahars of Scheduled Caste community. After embracing Buddhism, they declined to do the traditional work and many of them out migrated(Kamble, 1983). Pointed out among the Scheduled Castes it is the Mahar community in Maharashtra which utilized the facilities better than any other Scheduled Castes community (Chitnis, 1975) because of social, cultural and religious influence of Buddhism than the other scheduled castes.

\section{REFERENCES}

[1] 'Budget has left out Dalit, Adivasi's from SabkaVikas', (02/03/2015), The Hindu, Business line

[2] Attack on Dalit A well organized Crime: Scheduled Castes Panel (13/11/2012), R. Arivanantham Hindu.

[3] Children from Scheduled Castes Most Vulnerable To Abuse: Study (5/1/2014), The Hindu.

[4] Dalit Muslims, Christians Demand Scheduled Caste Status, (16/11/2012), The Hindu.

[5] Das Suranjan (2013): "Health culture of Scheduled caste: A Case Study of Patni in Cachar District of Assam" International Research Journal of Social Sciences, Vol. 2(12), 35-41, December (2013)

[6] Government Diverted Funds for Scheduled Castes: NGO (9/7/2012), Deccan Herald.

[7] JaganKarade (2014): Occupational Mobility among the Scheduled Caste in Maharashtra, an International Peer Reviewed, Scholarly Research Journal for Interdisciplinary Studies, Vol. II/XI, March-April, 2014

[8] K. C. Ramotra (2000): Impact of Development Processes on the Scheduled Caste of Maharashtra: A Spatial Perspective

[9] Lancy lobo, (1994): Dominant caste and atrocities on scheduled castes in Gujarat, Journal of Dalit and Bahujan studies, Vol. 1. No. 1, Jan / April1994, P.P.39-43

[10] N. D. Kamble (1983): Deprived Castes and Their Struggle for Equality, Ashish Publishing House, New Delhi.

[11] Neeru Sharma: Caste in Punjab: Political Marginalization and Cultural Assertion of Scheduled Castes in Punjab, Jawaharlal Nehru University, New Delhi.

[12] Parties Shut Out Scheduled Caste Candidates from General Seats (3/5/2014), Rukmini S., The Hindu.

[13] Rukhsana and AsrafulAlam (2014): Literacy Differentials among Scheduled Caste and Non-Schedule Castes in West Bengal, India: A District Wise Study, International Journal of innovative Research in Science, Engineering and Technology, Vol. 3, Issue 3, March 2014

[14] Scheduled caste quota in plots being misused: High Court (11/02/2014), Saurabh Mauk, Tribune.

[15] Scheduled Caste Slum Dwellers to Get 15,000 Flats Free Of Cost, (17/9/2011), Rajesh Kumar, Pioneer.

[16] Scheduled Caste status for Dalit Christians, Muslims sought, (3/6/2013), The Hindu.

[17] Suma Chitnis (1975): "Education of the Scheduled Castes", Joumal of Higher Education, Vol. I (2), pp.167-178.

[18] US Department of State (2006): India Country Reports on Human Rights Practices - 2005, 8 March - Attachment 1

[19] Wankhede G.G. (2001): 'Educational Inequalities among Scheduled Castes in Maharashtra' in Economic and Political weekly. Vol.36No.18, pp. $1553-1558$. 